\title{
Coercion, Obnoxious Tasks, and Economic Efficiency ${ }^{\mathrm{a}}$
}

\author{
Soham Baksi ${ }^{*}$ Pinaki Bose ${ }^{* *}$, and Marc T. Law ${ }^{* * *}$
}

\begin{abstract}
Incomplete contracts and inadequate enforcement of labor rights, together with the asymmetry of power between a worker and her employer, create an environment where the employer can forcibly extract additional services (e.g. unpaid overtime or sexual favors) from the worker beyond the mutually agreed terms of exchange. We show that coercive impositions can co-exist with voluntary transactions in the labour market, and that a positive incidence of coercion can adversely affect the efficiency of the corresponding market transactions. This may justify banning the legal market for the additional service if it is regarded as "obnoxious" by society.
\end{abstract}

JEL Classification: O17, D61, D82

Keywords: workplace; harassment; coercion; economic efficiency

* Department of Economics, University of Winnipeg, MB R3B 2E9, Canada. E-mail: s.baksi@uwinnipeg.ca

** Department of Economics, University of Manitoba, Winnipeg, MB R3T 5V5, Canada. E-mail: Pinaki.Bose@, umanitoba.ca

*** Department of Economics, University of Vermont, Burlington, VT 05405, USA. Email: Marc.Law@uvm.edu

${ }^{a}$ We thank J. Atsu Amegashie, Arnab Basu, Kaushik Basu and Mukesh Eswaran for their comments. The usual disclaimer applies. 


\section{Introduction}

Coercive behaviour by employers has become an increasingly salient public policy issue. Workplace coercion can take many forms. Sometimes it involves sexual harassment or the expectation that employees perform sexual services for bosses in addition to their usual jobs. The \#MeToo movement has brought to light many high profile examples of top ranking executives accused of harassing their workplace subordinates. ${ }^{1}$ In other instances, it involves compelling employees to work overtime without extra pay, or having their wages or tips appropriated by their employers. ${ }^{2}$ A survey of low wage workers in three major US cities in 2008 found that 76 percent of workers who worked in excess of 40 hours per week were not paid legally required overtime, that 26 percent were paid less than the legally mandated minimum wage, and that 12 percent of tipped workers experienced illegal tip stealing by their employers (Bernhardt et al 2009). The evidence from the \#MeToo movement as well as the low wage worker survey indicates that affected employees often feel intimidated into compliance by their superiors. ${ }^{3}$

In spite of its prevalence, coercion in the workplace has not been extensively studied by economists. This is, perhaps, unsurprising as the canonical model of the labour market is one of purely voluntary exchange. In the standard framework, no worker is compelled to perform any task involuntarily. Labour contracts are assumed to be complete and there is no asymmetry of power between workers and their employers. While this is a useful simplification for some purposes, the evidence above suggests that it may not always be realistic. In the real world, labour market contracts are incomplete, the enforcement of labour laws not always effective, and workplace relationships are hierarchical yet proximate, generating opportunities for employers to covertly coerce their subordinates. ${ }^{4}$ Formal models of power, patronage, or bondage exist in the

\footnotetext{
${ }^{1}$ For a few notable examples, see the following link: https:/www.nytimes.com/interactive/2018/10/23/us/metooreplacements.html. It is worth mentioning that not every example from the \#MeToo movement involves boss harassing an employee. Nevertheless, in many cases, the circumstances involved a superior coercing a subordinate in a workplace setting.

${ }^{2}$ For example, class action lawsuits brought against some Canadian banks in 2007 accused them of a widespread practice of forcing employees to work overtime without additional compensation. Aggrieved bank workers covered by the suit complained about employer pressure to work beyond their regular hours, while being actively discouraged to claim overtime pay. While Scotiabank settled the lawsuit in 2014, the Ontario Superior Court ruled against CIBC in 2020. See https://www.cbc.ca/news/business/cibc-overtime-lawsuit-1.5515058

${ }^{3}$ Bernhardt et al (2009) found that 20 percent of workers reported that they had either complained to their employer or attempted to form a union. Of those, over 40 percent reported that they had experienced illegal employer retaliation, in the form of firings, suspensions, threats to cut hours or pay, or other similar attempts at intimidation. ${ }^{4}$ For the same reasons, employers may find it easier to intimidate employees rather than strangers into performing certain tasks.
} 
literature (e.g. Basu 1986; Bardhan 1991; Platteau 1995; Mukherjee and Ray 1995; Genicott 2001 and Motiram 2007), but these models do not explicitly incorporate coercive impositions into their analysis. Basu (2003) examines the impact of harassment of workers by their employees in a competitive labour market, but in his framework, harassment is not coercively imposed on workers. Bac (2018) studies co-worker harassment within firms using a principal-agent framework. His model generates useful insights regarding the relationship between firm-level organizational structure, wages and harassment, but does not address coercive impositions by employers and the welfare consequences.

In this paper, we develop a model that explicitly allows for the possibility of employer coercion in the workplace and we analyze its implications for labour market equilibrium and efficiency. ${ }^{5}$ In this model, employers hire workers to complete two potential tasks - a primary task, for which the worker is hired and paid, and a secondary task, which may or may not be explicitly contracted for. The secondary task could be an extension of the primary task (for instance, overtime work), or it may be an entirely different job. It may be legal to pay for its voluntary performance (as in the case of overtime pay) or illegal to do so (as in the case of sexual harassment or favours). In our model, the employer can choose between paying for the voluntary provision of the secondary task, or obtaining it via coercion. Employees have the same disutility from performing the primary task, but differ with respect to their disutility from performing the secondary task. We find that if the threat of coercion does not exist and the secondary task is explicitly contracted for, it is always performed efficiently (i.e. the secondary task is only performed by those workers whose disutility from performing it is less than their employers' return from it). However, when the threat of coercion exists and is anticipated by employees, it has a negative impact on economic efficiency that spills over, as an externality, onto voluntary transactions: employers pay for secondary tasks to be performed, even when those tasks are inefficient.

Further, we analyze the welfare implications of coercive impositions of the secondary task, allowing for the possibility that the task is "obnoxious" in nature. ${ }^{6}$ To the extent that society at large perceives the secondary task to be undesirable (say, on moral grounds), its performance by individuals, even on a voluntary basis, can impose external (e.g. psychic) costs on society. ${ }^{7} \mathrm{We}$

\footnotetext{
${ }^{5}$ Coercion among co-workers is also an important issue, but not one that we investigate here.

${ }^{6}$ See Kanbur (2004) and Satz (2004) for a formal definition of obnoxious tasks, and Roth (2007) for a review.

${ }^{7}$ There is evidence, for instance, that sexual harassment at work harms productivity and family relationships (see

Raver and Gelfand 2005; Willness et al 2007; and Xin et al 2018). As Roth (2007, page 40) notes, "Some markets
} 
find that, if the secondary task imposes an external cost on society, the banning of contracts involving the voluntary performance of such tasks is more likely to improve welfare when coercive imposition of these tasks is possible.

Our analysis applies to coercive situations in modern workplaces (as described earlier) as well as informal labor markets in less developed countries. There are many examples of traditional employer-employee relationship where contracts are informal and their enforcement is at the mercy and discretion of the socially powerful employer. Labor tying arrangements, such as bonded labor or patron-client relationships, are forms of indentured servitude of the poorer members (the clients) to the affluent persons (the patrons) of a community. In such arrangements, the patron is expected to provide material assistance, in return for which the client is expected to reciprocate with provision of labor services, as well as deferential and obedient behavior. The responsibilities of the domestic servant or the bonded agricultural labourer are often ill-defined and, for all practical purposes, they serve at the beck-and-call of their employers. As Fafchamps (1992) notes, the patron possesses the power and ability to turn this work relationship into "an instrument of exploitation.” Breman (1974) in his study of bonded labour in south Gujarat, India, shows that the employer, because of his social power, can frequently impose additional burden of work on the labourer.

The remainder of this paper is structured as follows. In Section 2, we develop a labour market model where there is the possibility of coercive imposition of additional tasks in the workplace. In Section 3, we derive the equilibrium in the model with and without coercion. In Section 4, we examine the welfare consequences of banning voluntary contracts involving the secondary task in the presence of coercion. This is followed by a conclusion.

\section{The Model}

Consider a competitive labour market where a number (or mass) of employers hire from a larger pool of employees. Normalizing the number of potential employees to 1 , the number of employers is given as $M$ (with $M<1$ ). Each employer hires one worker. There are two potential tasks - a

are banned or limited for combinations of reasons that include both repugnance and also concerns about negative externalities. For example, limits on prostitution or pornography depend in part on revulsion at commercializing sex." 
primary task (task 1) and a secondary task (task 2). These tasks generate returns of $Y_{1}$ and $Y_{2}$ respectively for the employer. The secondary task is a related opportunity, or an extension of the primary task, that arises while task 1 is being performed. The nature of the secondary task is such that it leaves the worker vulnerable to exploitation by the employer - the employer may coerce his employee to perform the task without payment. No such opportunity for coercion exists with respect to the primary task. ${ }^{8}$ Sexual harassment faced by an employee in her workplace, or additional/overtime work demanded by an employer, constitute examples of the secondary task. Because such tasks are performed on the sidelines of a primary task, they leave the employee vulnerable to coercion.

An employee's disutility or cost of performing the primary task is $v$, and her disutility for the secondary task is $c$. Employees are heterogeneous in their types in terms of $c$, with $c$ distributed uniformly over $[0,1]$. The type of an employee is private knowledge to her, i.e. it is unknown to any employer or other workers. Since $M$ denotes the mass of employers, each of whom employs one worker, $M$ will also be the highest type of an employed worker.

One of the following two kinds of contracts is offered by each employer: (i) a "harassment contract" (contract $H$ ), which requires performance of both the tasks by the worker, and (ii) a "nonharassment contract" ( contract $N$ ), which formally calls for performance of the primary task only. ${ }^{9}$ A worker who seeks employment is free to choose either contract. If she chooses the $H$ contract, then the employee agrees to voluntarily perform the secondary task, along with the primary task, in return for compensation $w_{H}$. On the other hand, by choosing the $N$ contract, the worker receives

\footnotetext{
${ }^{8}$ Thus, we regard the terms of the primary task to be the basic employment contract, which is visible and enforceable. This is quite realistic - even in traditional work relationships the patron engages the client for some stipulated remuneration, and social pressure or considerations of continuity of the relationship usually ensures that this remuneration is paid.

${ }^{9}$ Thus, by definition, the harassment contract is the one where the employer pays a wage the covers payment for both tasks. The worker who accepts this contract voluntarily complies with the demand for performance of the secondary task on top of her primary duties. The terminology follows Basu (2003); the harassment contract is one under whose terms employers formally retain the right to harass workers, i.e. to make them perform obnoxious secondary tasks in return for an appropriate wage. The non-harassment contract is one where employers formally contract for the performance of only the primary task. In Basu (2003), where coercion is not modeled, this guarantees non-occurrence of the secondary task for those who sign the non-harassment contract. In our model, where the employer can coercively harass his worker without compensation, the two contracts represent his alternatives between payment for voluntary performance and coercive imposition of the secondary task.
} 
a wage of $w_{N}$ and faces the possibility of being coerced into performing the non-contracted secondary task without additional (i.e. over and above $w_{N}$ ) compensation. ${ }^{10}$

Employers offer their contracts, following which workers self-select among the various offers, or choose to stay unemployed. A worker who chooses the $N$ contract expects a positive probability of being subjected to coercion. To focus on the interior equilibrium where both the contracts are offered, we assume that $Y_{1}>v$ and $Y_{2}<M$. Further, all agents are assumed to be risk neutral and have zero reservation income.

\section{Equilibrium}

\subsection{Case A: Equilibrium without Coercion}

As a benchmark, we first derive the equilibrium when the possibility of coercion does not exist. Then the only way an employer can get the secondary task performed is by compensating his employee for it. Since $Y_{1}>v$ and the number of potential employees exceeds the number of employers, competition ensures that the wage associated with the $N$ contract, under which an employee performs only the primary task, will be $w_{N}^{*}=v$. An employer offering the $N$ contract earns $Y_{1}$ and pays $w_{N}^{*}$ to his employee. If he offers the $H$ contract, his revenue is $Y_{1}+Y_{2}$ and his cost is $w_{H}^{*}$. Since an employer is free to offer the $N$ contract or the $H$ contract, in the interior equilibrium where both contracts are offered, the employers will be indifferent between the two kinds of contracts. Hence, we have

$$
Y_{1}-w_{N}^{*}=Y_{1}+Y_{2}-w_{H}^{*}
$$

when

$$
w_{H}^{*}=Y_{2}+w_{N}^{*}=Y_{2}+v
$$

On the other hand, an employee will prefer the $H$ contract over the $N$ contract if and only if

\footnotetext{
10 The terms of payment of all contracts are perfectly enforceable. Thus, coercion takes place only in the case of the $N$ contract, when the employer imposes what he has not contracted for earlier.
} 


$$
w_{H}^{*}-v-c \geq w_{N}^{*}-v
$$

Thus, the marginal employee - one who is indifferent between choosing the $H$ or the $N$ contract will have a secondary task disutility of

$$
c^{*}=w_{H}^{*}-w_{N}^{*}=Y_{2}
$$

All employees with $c \leq Y_{2}$ will choose the harassment contract with wage $w_{H}^{*}$, while those with $c>Y_{2}$ will choose the non-harassment contract with wage $w_{N}^{*} \cdot{ }^{11}$ A total of $M$ workers, of types 0 $\leq c \leq M$ will be employed (one per each employer). Figure 1 represents the equilibrium in the absence of coercion. Proposition 1 follows from the above.

Proposition 1: When an employer cannot coercively impose the secondary task on his employee, it is always performed efficiently. This is because the secondary task is performed by only those workers whose disutility of performing the task is not greater than their employers' return from it.

Social welfare includes the welfares of the employers and workers. Moreover, if the secondary task is an obnoxious one (such as sexual harassment), its existence can impose a negative externality or a psychic cost on society and reduce social welfare. We use a utilitarian welfare function where social benefits are the aggregate of employer and worker utilities (with equal weight on each), and the negative externality of the obnoxious secondary task is convex in the number of workers performing that task (either voluntarily or, as in case B, under coercion). ${ }^{12}$ Social welfare in Case A is

$$
W_{A} \equiv \int_{0}^{Y_{2}}\left(Y_{1}+Y_{2}-v-c\right) d c+\int_{Y_{2}}^{M}\left(Y_{1}-v\right) d c-\alpha Y_{2}^{2}=M\left(Y_{1}-v\right)+1 / 2 Y_{2}^{2}-\alpha Y_{2}^{2}
$$

\footnotetext{
${ }^{11}$ Unlike as assumed, if $Y_{2} \geq M$, then the only contract offered by all employers would be harassment contract with $w_{H}^{*}=v+M$.

12 The external cost can be convex because it may be possible to overlook or downplay a few cases of employee harassment as anomalies, while a large number of such cases may be harder to ignore or may shape public opinion.
} 
where $\alpha \geq 0$ is the negative externality parameter, and $\alpha Y_{2}^{2}$ represents the external cost of harassment in Case A. If $\alpha=0$, the secondary task does not impose a negative externality on society. Wages being transfer payments do not enter (3).

Note that coercion is possible unless we make the strong assumption that the employers can commit to eschewing future acts of coercive impositions when offering the $N$ contract. Although an employer who offers the $w_{N}$ contract promises ex-ante (i.e. before the worker chooses the contract) not to coerce his worker, he will find it ex-post optimal (after the $w_{N}$ contract has been chosen by the worker) to do so. ${ }^{13}$ Workers rationally expect this and, in equilibrium, the acceptable $w_{N}$ incorporates this expectation. Unless the employers possess specific commitment mechanisms, their commitment not to harass will lack credibility with the workers. We assume such inability to credibly pre-commit on part of the employers, and analyze the resulting equilibrium in Section 3.2.

\subsection{Case B: Equilibrium with Possibility of Coercion}

Case B allows for the possibility of coercion taking place. Specifically, an employer whose employee choses the $N$ contract gets, with probability $m$, an opportunity to impose, without compensation, the non-contracted secondary task on her. The cost to the employer of such coercive imposition is denoted by $r$ (with $r<Y_{2}$ ). This cost $r$ could reflect, for instance, the employer's psychic cost of coercing and/or the precautions he has to take in order to keep the imposition covert.

In this situation, a worker will choose the non-harassment contract if and only if

$$
w_{N}-v-m c>\max \left\{0, w_{H}-v-c\right\}
$$

or,

$$
\frac{w_{H}-w_{N}}{1-m}<c<\frac{w_{N}-v}{m}
$$

\footnotetext{
${ }^{13}$ As $Y_{1}-w_{N}^{*}+m\left(Y_{2}-r\right)>Y_{1}-w_{N}^{*}$, where $m$ and $r$ are defined in section 3.2.
} 
Note that $\frac{w_{H}-w_{N}}{1-m}<\frac{w_{N}-v}{m}$ is satisfied whenever

$$
w_{N}>m w_{H}+(1-m) v
$$

All workers with $c \leq \frac{w_{H}-w_{N}}{1-m}$ will choose the harassment contract. This is because $w_{H}-v-c>0$ for all $c \in\left[0, \frac{w_{H}-w_{N}}{1-m}\right]$, whenever (6) is satisfied.

The wages associated with the two contracts can be determined as follows. In the interior equilibrium of our model, the worker with the highest $c$ to be employed (alternatively, the last worker to be employed) will be the one who is indifferent between accepting the $N$ contract and remaining unemployed. Since this worker's disutility from performing the secondary task equals $M$, her participation constraint will ensure that

$$
w_{N}^{* *}=v+m M
$$

Moreover, since employers are free to offer either $H$ or $N$ contracts, the equilibrium harassment wage will be such that an employer is indifferent between the two contracts, i.e.

$$
Y_{1}+Y_{2}-w_{H}^{* *}=Y_{1}-w_{N}^{* *}+m\left(Y_{2}-r\right)
$$

or,

$$
w_{H}^{* *}=w_{N}^{* *}+(1-m) Y_{2}+r m=Y_{2}+v+m\left(r+M-Y_{2}\right)
$$

Given these values of $w_{N}^{* *}$ and $w_{H}^{* *}$, satisfaction of condition (6) requires

$$
M>Y_{2}+\frac{m r}{1-m}
$$


We assume that parameter values are such that the inequality in (10) is satisfied. ${ }^{14}$

Furthermore, the marginal employee, who is indifferent between choosing the $H$ or the $N$ contract, has a secondary task disutility of

$$
c^{* *} \equiv \frac{w_{H}^{* *}-w_{N}^{* *}}{1-m}=Y_{2}+\frac{m r}{1-m}>c^{*}
$$

where $c^{*}=Y_{2}$ from (2). Figure 2 represents the equilibrium in the presence of coercion.

The possibility of coercive imposition of the secondary task by employers implies an additional expected cost (or disutility) of accepting the $N$ contract for the workers. This causes $w_{N}^{* *}$ to be higher than $v$, the corresponding wage for the $N$ contract in the absence of coercion. The wage for the $H$ contract also rises above $w_{H}^{*}=v+Y_{2}$, as otherwise employers find the $H$ contract more profitable. ${ }^{15}$ Consequently, in equilibrium, there are more employers offering the $H$ contract, compared to the benchmark case. The possibility of coercion also leads more employees to choose the harassment contract and voluntarily perform the secondary task. Comparing with the equilibrium outcome of section 3.1, as represented by Figure 1, it is easy to see that there is an additional mass of employees, of types $c \in\left(Y_{2}, Y_{2}+\frac{m r}{1-m}\right)$, who now voluntarily perform the secondary task. However, since $c$ exceeds $Y_{2}$ in this interval, it is inefficient for them to do so, as their disutility of performing the secondary task exceeds the return from that task. Thus, a positive incidence of coercive acquisitions has a spillover effect on the terms and the efficiency of voluntary exchanges. The probability, $\phi$, of such voluntary but inefficient performance of the secondary task taking place is

$$
\phi=\frac{c^{* *}-c^{*}}{M}=\frac{m r}{(1-m) M}
$$

Formally, we have Proposition 2.

\footnotetext{
${ }^{14}$ Recall that we have already assumed (in section 2) that $M>Y_{2}$. If $M$ exceeds $Y_{2}$ by at least the amount $m r /(1-m)$, the interior equilibrium of section 3.2 will emerge.

${ }^{15} \mathrm{It}$ is interesting to note that not only the non-harassment wage, $w_{N}^{* *}$, but even the harassment wage, $w_{H}^{* *}$, is an increasing function of the probability of coercion $m$. From (9), we have $\frac{\partial w_{H}^{* *}}{\partial m}=r+M-Y_{2}>0$.
} 
Proposition 2: When coercive imposition of the secondary task is possible, voluntary performance of the secondary task takes place even when it is inefficient. This occurs with probability $\phi$, as given by equation (12). Consequently, social welfare is less than that in Case A of no coercion.

The proof of this proposition is evident from the preceding analysis and Figures 1 and 2 . Note that Proposition 2 holds irrespective of the value of $\alpha$, the negative externality of harassment parameter. Thus, even if society did not find the secondary task obnoxious (i.e. $\alpha=0$ ), the very possibility of its coercive imposition can lead to some inefficient performance of the task through voluntary market-based transactions.

The total number of employees performing the secondary task in Case $\mathrm{B}$ is $c^{* *}+m\left(M-c^{* *}\right)$. Substituting the value of $c^{* *}$ from (11), we have social welfare in this case as

$$
W_{B} \equiv \int_{0}^{Y_{2}+\frac{m r}{1-m}}\left(Y_{1}+Y_{2}-v-c\right) d c+\int_{Y_{2}+\frac{m r}{1-m}}^{M}\left(Y_{1}-v+m\left(Y_{2}-r-c\right)\right) d c-\alpha\left(Y_{2}+\frac{m r}{1-m}+m\left(M-Y_{2}-\frac{m r}{1-m}\right)\right)^{2}
$$

It is easy to check that $W_{A}$ is strictly greater than $W_{B}$ even if $\alpha=0$. Inefficiency in case B results from both the coercive imposition of the secondary task as well as from the voluntary performance of it by employees whose type $c$ satisfy $Y_{2}<c \leq Y_{2}+\frac{m r}{1-m}$. The positive incidence of coercion exerts a negative externality on the non-coercive labour market for the secondary task even if $\alpha=$ $0 .{ }^{16}$

\footnotetext{
${ }^{16}$ Note that $W_{B}$ increases when the probability of coercion $m$ decreases. This is because, from (10) and (13), we have $\frac{\partial W_{B}}{\partial m}=-\frac{((1-m) Z+r)\left((1-m)\left(M-Y_{2}\right)-m r\right)}{2(1-m)^{2}}-2 \alpha Z\left(m Z+Y_{2}\right)<0$, where $Z \equiv M+r-Y_{2}>0$. Moreover, when $m=0$, we have $\left.W_{B}\right|_{m=0}=M\left(Y_{1}-v\right)+\frac{1}{2} Y_{2}^{2}(1-2 \alpha)=W_{A}$. While the body of the paper assumes that $m$ is an exogenous parameter, in the Appendix we endogenize $m$ by considering costly anti-coercion activities by the government.
} 


\section{An Efficiency Argument for Banning Harassment Contracts in the Presence of Coercion}

Can elimination of markets for obnoxious secondary tasks be justified from an efficiency standpoint? ${ }^{17}$ In the absence of coercion (as in the benchmark Case A), banning the harassment contract would imply that only the primary task would be undertaken. ${ }^{18}$ Social welfare in that case would be

$$
W_{A}^{\text {ban }} \equiv \int_{0}^{M}\left(Y_{1}-v\right) d c=M\left(Y_{1}-v\right)
$$

Superscript "ban" on the welfare function is used to denote the situation where the harassment contract is prohibited, so that only the non-harassment contract prevails in the market. From (3) and (14), banning the $H$ contract increases welfare in the absence of coercion (i.e. $W_{A}^{\text {ban }} \geq W_{A}$ ) if and only if

$$
\alpha \geq 1 / 2
$$

When coercion is possible (as in Case B), preventing market transactions in the harassment contract would imply that all $M$ workers would receive the non-harassment contract and get coerced into performing the secondary task with probability $m$. Social welfare in this case would be

$$
W_{B}^{b a n} \equiv \int_{0}^{M}\left(Y_{1}-v+m\left(Y_{2}-r-c\right)\right) d c-\alpha(m M)^{2}
$$

\footnotetext{
${ }^{17}$ Deontological considerations can also justify disallowing market transactions in obnoxious tasks.
}

${ }^{18} \mathrm{We}$ are abstracting away from enforcement issues here for simplicity. 
In the above computation of $W_{B}^{b a n}$, we assume that the ban only disallows employers from offering the $H$ contract. The opportunity for covert coercion remains the same as before, in the absence of additional regulatory measures to decrease $m$.

From (13) and (16), it is seen that banning the $H$ contract increases welfare (i.e. $W_{B}^{b a n} \geq$ $W_{B}$ ) if and only if

$$
\alpha \geq \frac{m r+Y_{2}(1-m)}{2(1-m)\left\{Y_{2}(1-m)+m(r+2 M)\right\}} \equiv \tilde{\alpha}
$$

Note that $\tilde{\alpha}<1 / 2$ as long as $2 M>Y_{2}+\frac{m r}{1-m}$; the latter inequality is satisfied whenever (10) holds. Thus, if the negative externality parameter is "small" (i.e. $\alpha<\tilde{\alpha}$ ) the harassment contract should be allowed, whereas if it is "large" (i.e. $\alpha>1 / 2$ ) the harassment contract should be banned, regardless of whether coercion exists or not. ${ }^{19}$ The interesting result emerges when $\alpha$ takes "intermediate" values (i.e. $\tilde{\alpha}<\alpha<1 / 2$ ). In such case, $W_{A}^{\text {ban }}<W_{A}$ and $W_{B}^{\text {ban }}>W_{B}$, i.e. banning the harassment contract improves welfare only in the presence of coercion but not in its absence. Formally, Proposition 3 follows.

Proposition 3: Existence of coercion can sometimes justify, from a welfare standpoint, the prohibition of market transactions involving obnoxious tasks. This happens when the negative externality of harassment parameter takes an intermediate value (i.e. $\tilde{\alpha}<\alpha<\frac{1}{2}$ ).

Banning the harassment contract has two counteracting effects on welfare. First, it prevents the secondary task from being voluntarily undertaken by even those workers whose cost of performing that task is less than their employer's benefit from it. This inefficiency tends to reduce social welfare (the "cost effect"). Second, banning the $H$ contract lowers the level of harassment, which tends to increase welfare by reducing the external cost of harassment ("benefit effect"). When coercion is absent, the cost effect of banning the $H$ contract dominates the benefit effect

\footnotetext{
${ }^{19}$ If $\alpha=0, W_{A}^{\text {ban }}<W_{A}$ and $W_{B}^{\text {ban }}<W_{B}$. In other words, when there is no external cost of harassment, banning the harassment contract reduces welfare both in the absence and presence of coercion.
} 
only when $\alpha<1 / 2$. However, existence of coercion alters both these cost and benefit effects such that the former dominates the latter only for smaller values of the externality parameter (i.e. $\alpha<\tilde{\alpha}<1 / 2) .{ }^{20}$ Consequently, blocking the harassment contract becomes desirable for smaller values of $\alpha$ when coercion is present than when it is not.

It is interesting to note that, if the social welfare function assigns different weights to the utilities of different individuals, a high enough emphasis on the net benefits of workers with $c \in$ $\left(Y_{2}, Y_{2}+\frac{m r}{1-m}\right)$, and their respective employers, can result in social welfare to be lower than $W_{B}$ as given by (13), conceivably to the extent that $W_{B}^{\text {ban }}>W_{B}$ even if $\alpha=0$. The utilitarian approach that we take here, with equal weights on all agents, is only one way of (subjectively) measuring social welfare. In an economy where the social planner gives higher weight to inefficient ventures, the spillover effects of coercive acts on the terms of market compensations may be sufficient to ban market transactions in the secondary task, even if it is not obnoxious. While we mention this in passing, we do not take this easy way out in demonstrating our result. Rather, with agents assigned identical weights in our welfare function, a strictly positive and sufficiently high value of $\alpha$ above a cutoff becomes essential for justifying a ban on harassment contracts. Nonetheless, it is important to recognize the complexity of the relationship between society's view of aggregate welfare and the optimality of banning, or legalizing, the market for a commodity which already thrives on the basis of covert deals and coercive acts.

\subsection{Numerical Example}

In this sub-section, we provide a numerical example in support of Proposition 3. Suppose the parameters in our model take the following values: $M=0.75, Y_{1}=0.9, Y_{2}=0.25, v=0.1, r=$ $0.05, m=0.3, \alpha=0.4$. Then condition (10) is satisfied as $M=0.75>Y_{2}+\frac{m r}{1-m}=0.27$. Moreover, $\tilde{\alpha}=0.21$, and the welfare levels corresponding to the above-defined cases are $W_{A}=$ $0.61, W_{A}^{b a n}=0.6, W_{B}=0.52$, and $W_{B}^{b a n}=0.54$. In other words, eliminating the market in secondary task increases social welfare when coercion is present but not when it is absent.

\footnotetext{
${ }^{20}$ By forcing some of the low-cost workers (i.e. those with $c \leq Y_{2}-r$ ) to perform the secondary task, coercion partially mitigates the inefficiency (cost effect) of banning the $H$ contract. However, at the same time, coercion itself adds to inefficiency by making some of the high-cost workers (those with $c>Y_{2}-r$ ) perform the secondary task.
} 


\section{Conclusion}

The analysis presented in this paper provides an interesting insight: a positive incidence of coercive acquisitions generates spillover external effects that distort the terms of trade and reduce the efficiency of voluntary market transactions. As formalized in Proposition 2, the existence of coercion lowers economic efficiency and welfare, compared to that in Proposition 1, irrespective of the magnitude of the negative externality imposed by the secondary task on society.

In this paper, we assign equal weight to the net benefit of each agent in our social welfare function. As discussed, this is not the welfare function that is the most conducive to demonstrating the results of section 4. But we are still able to justify circumstances for banning legal transactions in obnoxious goods - this points to the robustness of our claims in Proposition 3.

When the commodity (or the secondary task) concerned is obnoxious, and society suffers a cost that is increasing in the amount of the commodity, the paper reveals that there can be serious qualifications to the view that allowing a legal market for the commodity reduces the problem of coercion and inefficiency. First of all, unless enforcement activities are stepped up significantly, legalization of market transactions, by itself, will not remove the incentive of coercive imposition. We demonstrate that, in equilibrium, a positive incidence of such coercive acts co-exists with free participation and voluntary payment. In reality, there is abundant evidence in the workplace of employers acquiring unpaid services by imposing them on their employees when they could have legally paid for those overtime work. Second, social welfare may be higher if market transactions in an obnoxious good are banned, even if employers continue to enjoy the same level of opportunity to coerce their workers after the ban.

Both in developed and developing economies, it is extremely difficult to eradicate acts of covert coercion, especially when the good or service involved is obnoxious and employees hold precarious jobs that leave them vulnerable to exploitation. Under these circumstances, a more realistic policy, albeit conditional and susceptible to change when enforcement activities become more effective, may be to impose a ban on certain market transactions. The present paper develops an analysis that is pertinent for such cases. 


\section{Appendix}

In this appendix, we consider a scenario where the government (or a social planner) is able to affect the level of $m$ by carrying out anti-coercion activities. Let variable $g$ denote the level of effort given by the government to reduce the probability of coercion $m$. We assume that $m=1-\frac{g}{g_{\max }}$, where $g \in\left[g_{\min }, g_{\max }\right]$, and $g_{\min }$ and $g_{\max }$ are parameters denoting the minimum and maximum values of $g$. The cost of effort level $g$ to the government is $\theta g^{2}$, where $\theta$ is a parameter. We assume that political and other factors force the government to engage in some minimum level of anticoercion activities, so that $g$ cannot be less than $g_{\min }$. Moreover, since its anti-coercion effort is costly and $m=0$ when $g=g_{\max }$, the government will never choose a level of $g$ that exceeds $g_{\max }$. The government chooses the level of $g$ so as to maximize social welfare net of its own cost i.e. $\omega_{B}=W_{B}-\theta g^{2}$, where $W_{B}$ is given by (13). Since coercion is ruled out by definition in the benchmark case $\mathrm{A}$, anti-coercion activities by the government is not relevant for that case.

The FOC for the government's net welfare maximization problem is

$$
\frac{\partial \omega_{B}}{\partial g}=F\left(g, \alpha, r, \theta, M, Y_{2}\right)=0
$$

where $F\left(g, \alpha, r, \theta, M, Y_{2}\right) \equiv \frac{2 \alpha Z\left(g_{\max }(M+r)-g Z\right)}{g_{\max }^{2}}+\frac{Z^{2}}{2 g_{\max }}-\frac{r^{2} g_{\max }}{2 g^{2}}-2 g \theta$ and $Z=M+r-Y_{2}$. The SOC requires that $\frac{\partial^{2} \omega_{B}}{\partial g^{2}}=-2 \theta-\frac{2 \alpha Z^{2}}{g_{\max }^{2}}+\frac{r^{2} g_{\max }}{g^{3}}<0$. We assume that parameter values are such that the SOC is satisfied. The optimal level of government effort, $\hat{g}\left(\alpha, r, \theta, M, Y_{2}\right)$, is given by the solution to (18). The corresponding probability of coercion can then be computed as $\widehat{m}=$ $1-\frac{\hat{g}}{g_{\max }}$.

After totally differentiating $F\left(g, \alpha, r, \theta, M, Y_{2}\right)$ and applying comparative statics technique, the effect of a change in any one of the parameters on $\hat{g}$ is given by

$$
\frac{d \hat{g}}{d x}=-\frac{\partial F / \partial x}{\partial F / \partial g}
$$


where $x$ represents one of the parameters $\alpha, r, \theta, M$ or $Y_{2}$. Since $\frac{\partial F}{\partial g}<0$ due to the SOC, the sign of $\frac{d \hat{g}}{d x}$ is the same as the sign of $\frac{\partial F}{\partial x}$. Consequently, the following result holds.

Result: The optimal level of the government's anti-coercion effort, $\hat{g}$, is higher when (i) the secondary task imposes a larger negative externality on society (i.e. $\alpha$ is higher), (ii) the size of the market, $M$, is larger, and (iii) the cost of the government's anti-coercion activities, $\theta$, is lower.

Proof: We have (i) $\frac{\partial F}{\partial \alpha}=\frac{2}{g_{\max }^{2}} Z\left(g_{\max }(M+r)-g Z\right)>0, \quad$ (ii) $\frac{\partial F}{\partial M}=\frac{1}{g_{\max }^{2}}\left(g_{\max } Z+\right.$ $\left.2 \alpha\left(2 Z\left(g_{\max }-g\right)+g_{\max } Y_{2}\right)\right)>0$ and (iii) $\frac{\partial F}{\partial \theta}=-2 g<0$. Note that $\frac{\partial F}{\partial M}>0$ even if $\alpha=0$.

Since $\widehat{m}=1-\frac{\hat{g}}{g_{\max }}$, the above-mentioned change in $\hat{g}$ is accompanied by an opposite change in the probability of coercion $\widehat{m}$.

Numerical example: Suppose the parameters in our model take the following values: $M=0.75$, $Y_{1}=0.9, Y_{2}=0.25, v=0.1, \alpha=0.4, r=0.05, \theta=0.6, g_{\min }=0.13$ and $g_{\max }=1$. Then the SOC is satisfied as $\frac{\partial^{2} \omega_{B}}{\partial g^{2}}<0$, and the level of government effort that maximizes $\omega_{B}$ is $\hat{g}=0.34$. Consequently, the probability of coercion is $\widehat{m}=1-\frac{\hat{g}}{g_{\max }}=0.66$. Moreover, the threshold values of $c$ that determine the number of $H$ and $N$ contracts are $c^{*}=Y_{2}=0.25$ and $c^{* *}=Y_{2}+$ $\frac{\widehat{m} r}{1-\widehat{m}}=0.35$. As assumed in (10), we have $M=0.75>Y_{2}+\frac{\widehat{m} r}{1-\widehat{m}}=0.35$. 
Figure 1: Equilibrium in Case A

\begin{tabular}{|l|l|l|}
\hline H contracts & N contracts & \\
\hline $0 \quad c^{*}=Y_{2}$ & $M$ & 1
\end{tabular}

Figure 2: Equilibrium in Case B

\begin{tabular}{l|l|l|l|}
\hline $\begin{array}{l}\text { Efficient } \\
\text { H contracts }\end{array}$ & Inefficient & $\begin{array}{l}\text { N contracts } \\
\text { with coercion }\end{array}$ & \\
\hline 0 & $c^{*}=Y_{2}$ & $c^{* *}$ & $M$
\end{tabular}




\section{References}

Bac, Mehmet. "Wages, Performance, and Harassment." Journal of Economic Behavior and Organization 145 (January): 232-248, 2018.

Bardhan, P., "On the Concept of Power in Economics”, Economics and Politics, 3: 265-277, 1991.

Basu, K., “One Kind of Power”, Oxford Economic Papers, 38: 259-282, 1986.

Basu, K., "The Economics and Law of Sexual Harassment in Workplace”, Journal of Economic Perspectives, 17(3): 141-157, 2003

Basu, K., "Coercion, Contract and the Limits of the Market", Social Choice and Welfare, 29(4), 559-579, 2007.

Bernhardt, Annette, Ruth Milkman, Nik Theodore, Douglas Heckathorn, Mirabai Auer, James De Filippis, Ana Luz Gonzalez, Victor Narro, Jason Perelshteyn, Diana Polson and Michael Spiller. Broken Laws, Unprotected Works: Violations of Employment and Labor Laws in America's Cities. New York, NY: National Employment Law Project, 2009.

Fafchamps, M., "Solidarity Networks in Preindustrial Societies: Rational Peasants with a Moral Economy”, Economic Development and Cultural Change, 41(1):147-176, 1992.

Breman, J., Patronage and Exploitation: Changing Agrarian Relations in South Gujarat, University of California Press, 1974.

Genicot, G., "Bonded Labor and Serfdom: A Paradox of Voluntary Choice", Journal of Development Economics, 67: 101-128, 2002.

Kanbur, R., “On Obnoxious Markets”, in S. Cullenberg and P. Pattanaik (editors), Globalization, Culture and the Limits of the Market: Essays in Economics and Philosophy. Oxford University Press, 39-61, 2004. 
Motiram, S., "Attached Labor Contracts in Agriculture: Results and Analysis from a Survey in South India”, Canadian Journal of Development Studies, 28 (1): 99-117, 2007.

Mukherjee, A. and D. Ray, "Labor Tying”, Journal of Development Economics, 47: 207-239, 1995.

Platteau, J., “An Indian Model of Aristocratic Patronage,” Oxford Economic Papers, 47: 636-662, 1995.

Raver, Jana L., and Michele J. Gelfand. "Beyond the Individual Victim: Linking Sexual Harassment, Team Processes, and Team Performance." Academy of Management Journal 48(3): 387-400, 2005.

Roth, Alvin E. 2007. "Repugnance as a constraint on markets." Journal of Economic Perspectives 21(3): $37-58$.

Satz, D., "Noxious Markets: Why Should Some Things Not be for Sale", in S. Cullenberg and P. Pattanaik (editors), Globalization, Culture and the Limits of the Market: Essays in Economics and Philosophy. Oxford University Press, 2004.

Willness, Chelsea, Piers Steel, and Kibeom Lee. "A Meta-Analysis of the Antecedents and Consequences of Workplace Sexual Harassment.” Personnel Psychology 60(1): 127-62, 2007.

Xin, Jie, Shouming Chen, Kwan, Ho Kwong Kwan, Randy K. Chui, and Frederick Hong-kit Yim. "Work-Family Spillover and Crossover Effects of Sexual Harassment: The Moderating Role of Work-Home Segmentation Preference.” Journal of Business Ethics 147 (3), 619-629, 2018. 